\title{
Decadal simulations of coastal geomorphic evolution in Liverpool Bay, UK
}

\section{James Sutherland, Kate Rossington, Richard Whitehouse, Belen Blanco, Julien L'Homme}

HR Wallingford, Howbery Park, Wallingford, Oxfordshire, OX10 8BA, UK

Presented at Coastal Sediments 2015, San Diego, California, USA, 11-15 May 2015.

\section{Abstract}

The coastal systems concept maintains that long-term coastal evolution can be modelled through integrated analysis of interacting coastal behaviours, so the most interesting scientific insights may emerge from interaction and feedback between system components This paper presents an application of this approach to an area of coastline between Formby Point and Blackpool within Liverpool Bay, north-west England, UK. A linked set of models (known as a composition) was formed using two instances of a one-line model, an aggregated estuary model and results from a coastal area model. Explicit linkages between model instances were formulated and applied, using the FluidEarth implementation of the OpenMI standard for data exchange during run-time.

\section{Introduction}

The needs of coastal management and the challenge posed by climate change are driving a shift in our approach to coastal erosion and flood risk management. Presently, meso-scale (10s of kilometers and 10s of years) coastal and estuarine evolution is poorly understood, being situated between more detailed knowledge of microscale sediment transport processes and of broader coastal evolution, informed by stratigraphy and by empirical analyses of past shoreline change. Progress is being made in the prediction of meso-scale evolution within the Integrating Coastal Sediments Systems (http://www.icoasst.net) project by developing a hierarchical modelling framework that consists of:

- Coastal and Estuarine Systems Mapping (Whitehouse et al., 2009, French et al., 2015) which defines an ontology of coastal landforms and human interventions and uses a formal mapping protocol to show sediment pathways between landforms and influences between structures and landforms;

- Reduced-complexity models of the evolution of the coastal system, represented by coastal landform models, that interact using the FluidEarth 2 implementation of the OpenMI 2 standard for data exchange at run-time (Harpham et al., 2014)

- Coastal area models to identify sediment pathways (especially large-scale pathways for fine sediments) that help to define the exchanges between the coast and offshore (Brown et al., 2015a, 2015b). 
This coastal systems concept maintains that long-term coastal evolution can be modelled through integrated analysis of interacting coastal behaviour, so the most interesting scientific insights may emerge from interaction and feedback between system components This paper presents an application of the reducedcomplexity modelling approach to an area of coastline between Formby Point and Blackpool within Liverpool Bay, north-west England, UK. The paper describes the study site, shows how the component model were chosen and defines the exchanges between them. Brief descriptions of the FluidEarth implementation of OpenMI and the software stack used to implement the composition are then provided. A discussion on the merits of this approach then follows.

\section{Study Area}

Liverpool Bay is a prototypical hypertidal shelf sea, where the regional dynamics are strongly influenced by the adjacent estuaries (Brown et al., 2015a). Tidal currents are strong, but it is the residual circulation which promotes sedimentation in estuaries and adjacent coasts with important morphodynamic implications. The sediment within the bay is mainly medium to fine sand. A simulation using realistic atmospheric and riverine forcing (Brown et al., 2015a) simulated the annual baroclinic circulation during 2008. Hourly current vectors at each vertical level within the water column were time-averaged to create regional maps of the depthvarying residual circulation. Velocity profiles were used to derive shear stresses, which gave bedload sediment transport rates, which were time-integrated to obtain the annual residual transport rates across the model domain. These show a west-to-east bedload transport, which provides a supply of sand towards the coastline.

The modelled area (Figure 1) is between Formby Point on the Sefton Coast and Blackpool on the Fylde coast and forms the central part of a predominantly low lying soft coastline between the River Mersey (Liverpool, to the south) and Morecambe Bay (to the north).

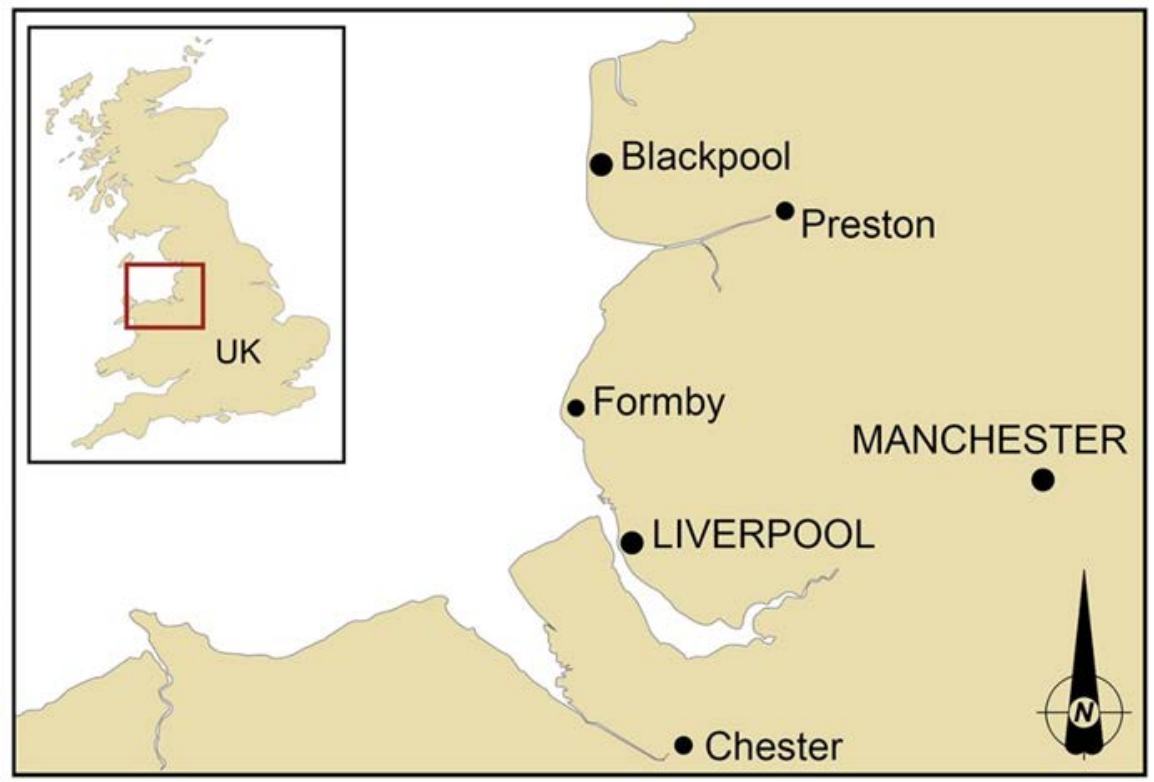

Figure 1 Study area 
The coastline around Formby Point consists of a wide, sandy foreshore, backed by dunes. These dunes are eroding at Formby Point with sediment accreting to north and south. Most of the coastline is undefended, with the main seawall at Southport, where the beach has become so wide that saltmarsh is starting to form. Continuing north, the cross-shore beach profiles becomes more estuarine, with saltmarsh becoming more common within the Ribble estuary.

The Ribble is naturally accreting and several areas, particularly on the southern side have been reclaimed. These give the potential for managed realignment, to reduce flood risk and re-create inter-tidal habitat. Extensive areas of sandy tidal flats are visible at low tide towards the center and mouth of the estuary.

The Fylde coast to the north of the Ribble, which includes Blackpool, is backed by the Wyre estuary. Again there are wide, sandy beaches with a dune system at Lytham (which has been largely built on). The only section of soft cliff within the study area is at Blackpool. This cliff has been protected by a seawall for decades. This holds the shoreline seawards of its natural position.

\section{Model Composition}

A composition is a set of linked numerical models that exchange information as they run. In this way a model of coastal erosion in one area can pass information on the volumes of sediment that leave it onto the next model in time for it to influence the behaviour observed in the second model. We have developed a composition of the coastline from Formby Point to Blackpool that links the following models: UnaLinea, ASMITA and POLCOMS. These three models were chosen as they represented the landforms and landform complexes identified by the Coastal and Estuarine System Mapping (Sutherland et al, 2015). This is a visual approach that was presented to stakeholders to get their opinions and to seek a consensus view on the landforms and key interactions on this coastline. This is therefore a participatory approach, which could be applied also to the selection of models and linkages in a composition.

The model instances are shown in Figure 2 and consist of a UnaLinea model of Formby Point to Southport (U1) an ASMITA model of the Ribble estuary (A1) a UnaLinea model of the Blackpool / Fylde frontage (U2) and model results from the 2008 POLCOMS simulation (P1) of Liverpool Bay (Brown et al, 2015). Details of models are provided in the following section.

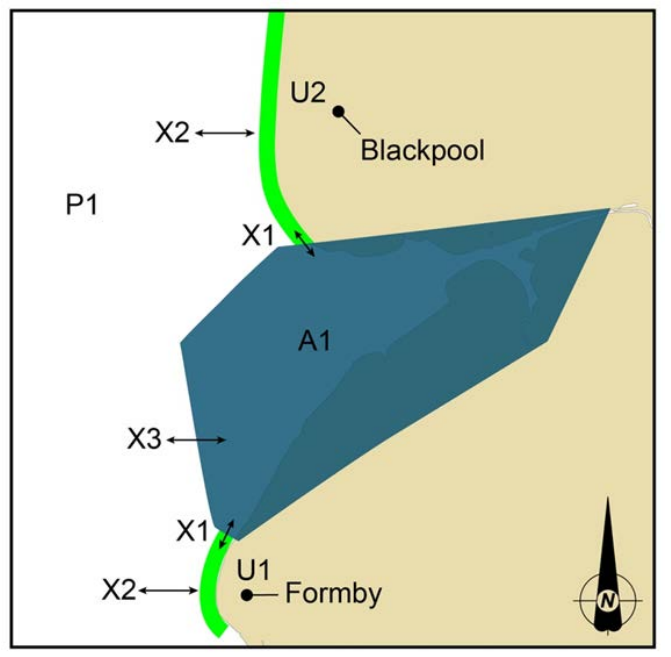

Figure 2 Model composition from Formby Point to Blackpool 
Model linkages are also shown in Figure 2 and consist of UnaLinea - ASMITA bi-directional links (X1), POLCOMS - UnaLinea links (X2) which are uni-directional and POLCOMS - ASMITA link (X3) which are uni-directional. Details of model linkages are also described below.

\subsection{Model linkages}

A recent study (Halcrow, 2010) used coastal area models, one-line models and estuary models to simulate the coastal systems in Liverpool Bay, including Formby to Blackpool. However, in this case, and in similar studies, models were run in isolation, with no sediment exchange between models and therefore, no attempt to conserve sediment. In this case explicit linkages have been derived, as explained below.

The UnaLinea - ASMITA bi-directional linkages are derived from assuming that sediment exchange is dominated by littoral drift $\left(Q, \mathrm{~m}^{3} / \mathrm{s}\right)$. The ebb tidal delta in ASMITA is linked to two instances of UnaLinea (U1 and U2) which predict a potential littoral drift ( $Q_{U 1}$ and $Q_{U 2}$ respectively) either into the ebb tidal delta (a supply) or out of it (a demand) as shown in Figure 3.

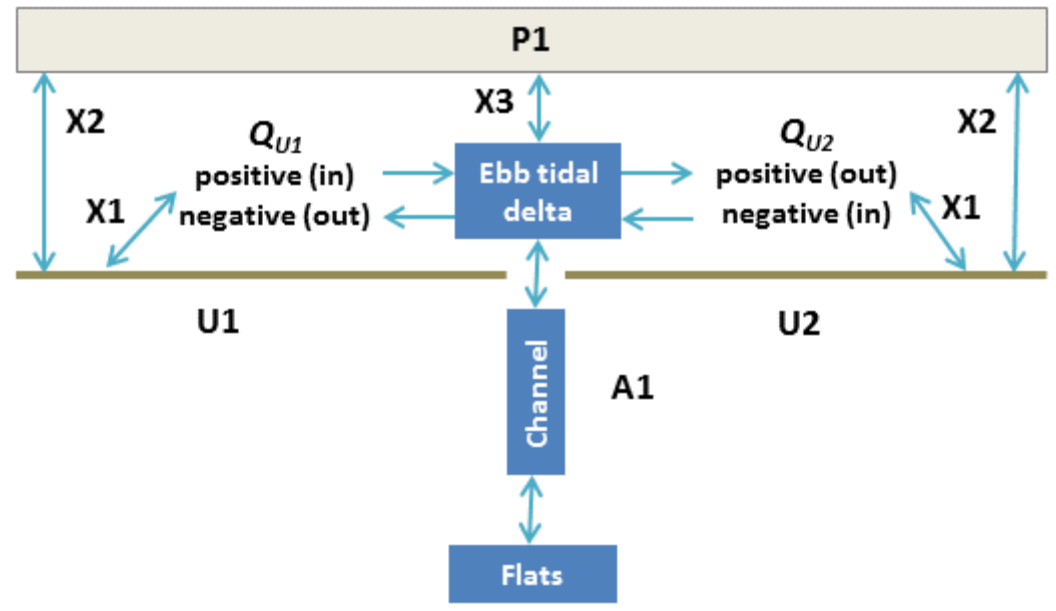

Figure 3 Links between ASMITA, UnaLinea and POLCOMS

Littoral drift could be directed towards the delta on both sides, away from the delta on both sides or towards the delta on onside and away on the other. In all cases the nett drift rate towards the delta (Qin) and away from the delta (Qdemand) are calculated (see Table 1 for details).

The rate of littoral drift predicted by UnaLinea is potential littoral drift (the littoral drift that will occur if unlimited sediment is available) and therefore when it is directed away from the ebb-tidal delta it will be controlled by the sediment availability in the delta. For this reason, potential drifts away from the ebb-tidal delta were considered demands and the ability of the estuary/delta system to meet the demand was calculated by modifying the Kraus (2000) model of sand bypassing at deltas. The rate at which sediment is passed from ASMITA to UnaLinea, Qout is given by Equation 1.

$Q_{\text {out }}=\left(\frac{V_{i}}{V_{E i}}\right)^{n} Q_{\text {demand }}$

Where $V_{i}$ is the sediment volume of the ebb-tidal delta, $V_{E i}$ is the equilibrium volume and $n$ is the sediment transport exponent from ASMITA. 
Table 1 Combinations of potential littoral drift, resulting demand and output

\begin{tabular}{ccccc}
\hline$Q_{\text {U1 }}$ & $Q_{\text {U2 }}$ & $Q_{\text {in }}$ & $Q_{\text {demand }}$ & $Q_{\text {out }}$ assigned to \\
\hline Positive (in) & Positive (out) & $\mathrm{Q}_{\mathrm{U} 1}$ & $\mathrm{Q}_{\mathrm{U} 2}$ & $\mathrm{U} 2$ \\
Negative (out) & Positive (out) & 0 & $\mathrm{Q}_{\mathrm{U} 2}-\mathrm{Q}_{\mathrm{U} 1}$ & $\mathrm{U} 1$ \& U2 (proportionally) \\
Positive (in) & Negative (in) & $\mathrm{Q}_{\mathrm{U} 1}-\mathrm{Q}_{\mathrm{U} 2}$ & 0 & No $\mathrm{Q}_{\text {out }}$ \\
Negative (out) & Negative (in) & $-\mathrm{Q}_{\mathrm{U} 2}$ & $-\mathrm{Q}_{\mathrm{U} 1}$ & $\mathrm{U} 1$ \\
\hline
\end{tabular}

The volume change of the delta resulting from littoral drift is then

$$
\frac{d V_{i}}{d t}=Q_{\text {in }}-Q_{\text {out }}
$$

In the ASMITA code, $Q_{\text {in }}$ and $Q_{\text {out }}$ are used to calculate the nett littoral drift volume and this is included in ASMITAs internal volume change calculations and therefore feeds back into equation 1 on the next time step.

In addition the ASMITA code was changed so that the equilibrium volume of ebb-tidal delta is in equilibrium with the long-term average littoral drift rate, so that changes in the littoral drift rate (from the long-term average) act as disturbances to the system and therefore influence the morphology.

Moreover, the $Q_{\text {in }}$ and $Q_{\text {out }}$ longshore drift rates were passed to each UnaLinea model (U1 and U2) at points slightly sway from the UnaLinea model boundaries, to avoid boundary effects. All points between the coupling point and the boundary are adjusted for the difference between the calculated potential drift rate and the value passed to or from ASMITA at the coupling point. On the up-drift side ( $Q_{\text {in }}$ in Table 1 ) this difference is zero. On the down-drift side ( $Q_{\text {demand }}$ in Table 1$)$ the difference is $Q_{\text {demand }}-Q_{\text {out }}=Q_{\text {demand }}(1-$ $\left.\left[V_{i} / V_{E i}\right]^{n}\right)$.

The POLCOMS - UnaLinea and POLCOMS - ASMITA links (X2 and X3 in Figure 2, respectively) are derived from POLCOMS results files. Gridded hourly time series of bedload transport rates were averaged to give monthly values. These were extracted from POLCOMS along a line that represented the approximate offshore limit of the coastal models, as represented by the inshore wave points for UnaLinea and the approximate offshore limit of the delta for ASMITA. These model results still have to be interrogated for seasonal and spatial variations, so the number of locations that data is transferred can be optimized and the variation in onshore feed through the year can be assessed.

The POLCOMS model results were pre-computed, so results files were used to provide the rate of sediment exchange. So although the direction of the links X2 and X3 may be onshore or offshore (i.e. have positive or negative values) these links are implemented as uni-directional links as the results from the coastal models cannot affect the results from POLCOMS. 


\section{FluidEarth implementation of OpenMI}

The need for integrated environmental modelling tools led to the development of the Open Modelling Interface, OpenMI (Gregersen et al. 2005, 2007). OpenMI (www.openmi.org) is a software component interface OGC standard (http://www.opengeospatial.org/standards/openmi) for numerical models that allows two-way exchange of data between compliant components as they run. A composition is formed when OpenMI compliant components are linked, so that they exchange data as they run. OpenMI is a generic solution to the problem of data exchange between models or software components. The generality was extended with the release of version 2.0 of the OpenMI Standard (OpenMI Association 2010) which added base interfaces, extensions and adaptors (between the output of one model and the input of another). The creation of an open modelling environment capitalises on the huge prior investment in model development, to ensure that the vast amount of encapsulated knowledge in existing (proprietorial) tools is not abandoned, but rather can be modernised, re-cycled and re-used.

iCOASST is using HR Wallingford's FluidEarth 2.0 (http://fluidearth.net) which is the Windows (.Net) reference implementation of the OpenMI 2.0 standard (Harpham et al., 2014). The FluidEarth software development kit (SDK) has been designed to make it relatively easy to make models (and other components) OpenMI compliant, while the GUI provides a user-friendly interface to allow users to assemble and run compositions of models. The FluidEarth GUI and SDK are open source and can be obtained from http://sourceforge.net/projects/fluidearth while a set of examples that use models and adaptors are provided at http://eLearning.fluidearth.net.

\section{Software implementation}

In order to create the composition, the models UnaLinea and ASMITA had to be made OpenMI compliant. UnaLinea is written in Fortran, which is one of the FluidEarth languages (the other being C\#) while ASMITA is written in Matlab (using $\mathrm{C}++$ ) which required the creation of a $\mathrm{C}++$ dll with a $\mathrm{C} \#$ wrapper. In both cases the existing code has to be structured into FluidEarth dlls. The structure of the code for ASMITA is shown in Table 2.

Table 2 Structure of ASMITA code for FluidEarth wrapping

\begin{tabular}{lll}
\hline FluidEarth DLL & ASMITA subroutines \\
\hline FLUIDEARTH2_ENGINE_INITIALISE & vardef & \\
FLUIDEARTH2_ENGINE_SETARGUMENT & & \\
FLUIDEARTH2_ENGINE_PREPARE & & \\
& asmita_lite & \\
& & cb_print \\
& ele_link & \\
& mu_meq & hw_vol \\
& & eq_vands \\
\hline
\end{tabular}




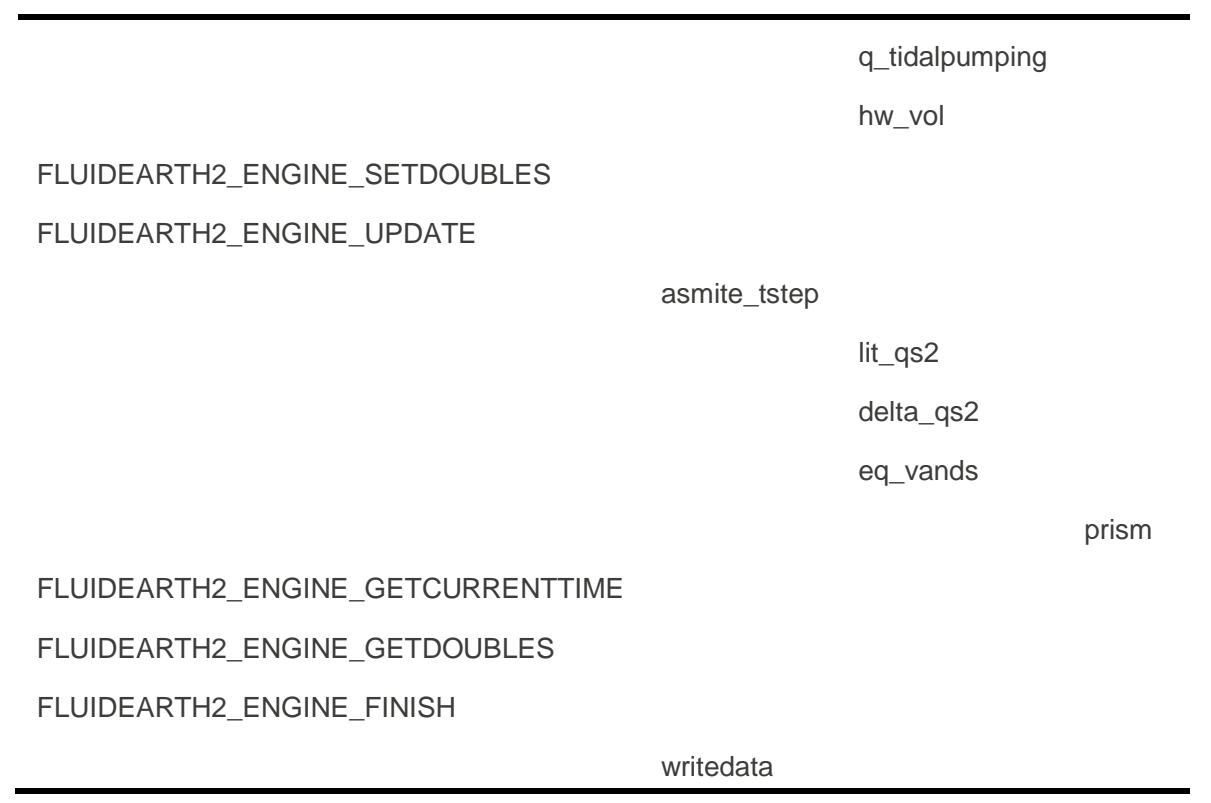

A simplified version of the software stack is shown in Figure 3, where the arrows indicate the logic control of processes. For example, the LiverpoolBay64.exe passes control to FluidEarth2 API to execute to composition. FluidEarth2 API passes control to UnaLinea and ASMITA OMI components, which in turn pass control to .NET 4.5 (UnaLinea) or MATLAB compiler runtime (ASMITA) and eventually control is passed to Windows 7.

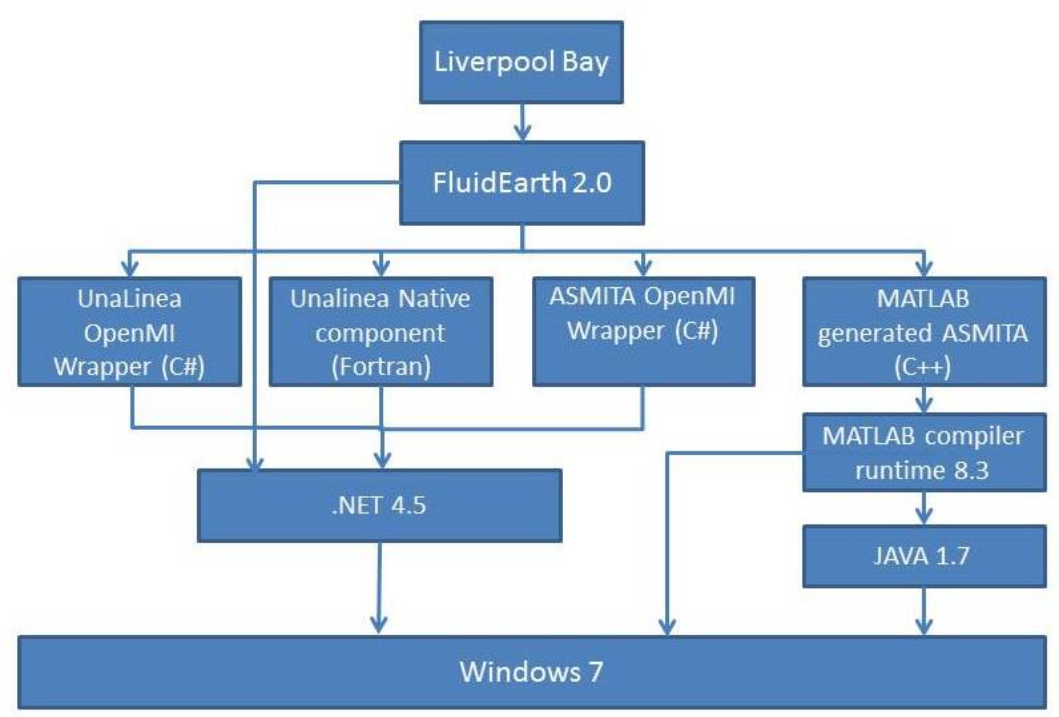

Figure 4 Simplified software stack

Figure 4 is not a complete mapping of dlls (see Table 2 for the number of dlls in MATLAB generated ASMITA alone) but is a partition of the system into its major components. 


\section{Status of the case study}

The Formby to Blackpool model composition has been developed to link together two instances of UnaLinea, one instance of ASMITA and the results from one instance of POLCOMS. UnaLinea and ASMITA have made into OpenMI compatible components using the FluidEarth SDK. Suitable exchanges of sediment between the models have been derived and implemented. The composition has been formed (Figure 3 ) and run with dummy models. Site-specific UnaLinea models have been set up for the coastlines around Formby Point and Blackpool. ASMITA has been set up for the Ribble estuary. Testing of these models is now under way.

\section{Discussion}

In order to simulate long-term coastal geomorphic evolution, we have used the FluidEarth 2 implementation of the OpenMI 2 software component interface standard to wrap existing models and link them to form a composition that exchanges sediment between component models at run-time. The component models chosen (UnaLinea and ASMITA) are reduced-physics, behavioural, landform-scale models that represent the key processes in modelling large-scale, decadal geomorphic evolution in a computationally feasible manner. These time and spatial scales were chosen to fit with the framework of coastal management in the UK and in particular with the system of Shoreline Management Plans (Defra, 2006) used in England and Wales.

This approach builds on the Coastal and Estuarine Systems Mapping and provides a picture of sediment transport and shoreline evolution that treats the coast as an interacting system. The CESM and the model composition can be used to engage with stakeholders over perceived validity and priorities, thereby seeking a degree of acceptance from stakeholders during the early stages of the modelling process. A key feature of this approach is the potential for the composition to be altered with the addition of modules for other processes, such as overwash, breach or dunes, depending on the needs of stakeholders. In the long-term this approach could link a morphology composition with flood risk assessment models or habitat / species models to look at the economic and environmental effects of coastal evolution.

The composition conserves sediment and has explicit linkages between models. These linkages can be challenged (as they are explicitly stated) and their effects can be tested. As different sources of data can be used within the composition (such as models, results files, historical averages and simple rules based on understanding of behavior) the best information is incorporated in a rigorous and internally consistent way (in that sediment is conserved).

This composition takes a few hours to simulate fifty years, so this approach lends itself to sensitivity analysis. An approach for undertaking sensitivity analysis using this composition has been developed. When implemented, sensitivity analysis will be used to identify important uncertainties, thresholds and the effects of different assumptions. Further engagement with stakeholders will be needed to identify the best way of communicating the information contained within the results from a sensitivity analysis, so that the results from models can be used to inform the dialogue about coastal management options.

\section{Conclusions}

Coastal erosion and flood risk management plans that cover the next one hundred years have been put in place for the coastline of England and Wales. The need to consider the potential influences of coastal geomorphic evolution on coastal and erosion risk management has driven the development of a systems- 
based approach, which involves setting up a composition of linked morphological models that represent different landforms and exchange data during run-time. Reduced-physics, behavioural, landform-scale models are used, that represent the key processes in modelling large-scale, decadal geomorphic evolution in a computationally feasible manner.

This approach is being trialed on a stretch of coast from Formby Point to Blackpool (including the Ribble estuary) in north-west England. A composition has been set up, consisting of two instances of the one-line model UnaLinea, one instance of the aggregated estuary model ASMITA, the results from one instance of the coastal area models POLCOMS and three types of sediment exchange. This composition should be capable of revealing uncertainties and sensitivities in the modelling process. It is intended that results from the composition should assist in making coastal management judgments more considered.

\section{Acknowledgement}

Integrating Coastal Sediment Systems (the iCOASST project) is funded by UK National Environmental Research Council (http://www.nerc.ac.uk) under grant NE/J00541X/1, with support from the Environment Agency (http://environment-agency.gov.uk).

\section{References}

Brown, J.M., Amoudry, L., Souza, A. and Rees, J. (2015a). "Fate and pathways of dredged estuarine sediment spoil in response to variable sediment size and baroclinic coastal circulation." Journal of Environmental Management, 149: 209-221.

Brown, J., Amoudry, L.O., Souza, A.J. (2015b). "Residual circulation modelling at the national UK scale to identify possible sediment pathways to inform decadal coastal geomorphic evolution models." Proceedings Coastal Sediments '15.

Defra, (2006). "Shoreline Management Plan Guidance volume 1: aims and requirements." Department for Environment, Food and Rural Affairs, PB 11726. Available from https://www.gov.uk/government/publications (accessed 1/2/2015).

French J, Burningham H. et al. (2015). "Conceptualizing and mapping coupled estuary, coast and inner shelf sediment systems." Geomorphology, in review.

Gregersen, J.B., Gijsbers, P.J.A., Westen, S.J.P. and Blind, M. (2005). "OpenMI: The Essential Concepts and their Implications for Legacy Software". Advances in Geosciences, 4, 37-44.

Gregersen, J.P., Gijsbers, P.J.A. and Westen S.J.P. (2007). "OpenMI: Open modelling Interface." Journal of Hydroinformatics, 9(3), 175-191. http://dx.doi.org/10.2166/hydro.2007.023.

Halcrow, (2010). "Cell Eleven Tidal and Sediment Transport Study (CETaSS) Phase 2 (ii) Main report summary of findings." Available from North West and North Wales Coastal Group.

Harpham, Q., Cleverley, P. and Kelly, D., (2014). "The FluidEarth 2 implementation of OpenMI 2.0". Journal of Hydroinformatics 16(4) 890 - 906, http://dx.doi.org/10.2166/hydro.2013.190

Holt, J.T. and James, I.D. (2001). "An s coordinate density evolving model of the northwest European continental shelf: 1, model description and density structure." J. Geophys. Res. 106 (C7), 14,015-14,034. 
Kraus, N. C. (2000). "Reservoir model of ebb-tidal shoal evolution and sand bypassing," Journal of Waterway, Port, Coastal, and Ocean Engineering 126 (3): 305-313.

OpenMI Association (2010). "OpenMI Standard 2 Specification for the OpenMI (Version 2.0)." Part of the OpenMI Document Series. http://www.openmi.org

Rossington, K., Nicholls, R.J., Stive, M.J.F. and Wang, Z.B. (2011). "Estuary schematisation in behaviouroriented modelling". Marine Geology, 281, 27-34.

Stripling, S. and Panzeri, M.C. (2009). "Modelling shoreline evolution to enhance flood risk assessment." Proceedings of the ICE - Maritime Engineering, 162(3) 137-144.

Stripling S, Panzeri M, Blanco B et al. (2011). "Broad scale integration of coastal flood and erosion risk models." FRMRC2 Work Package 4.3 Science Report. http://web.sbe.hw.ac.uk/frmrc/ (accessed 04/02/2015).

Sutherland, J., Nicholls, R.J., Burningham, H., Rossington, K., San Roman Blanco, B.L. and Brown, J.M., (2015). "Representing and modelling coastal systems over a regional scale for coastal management." Proceeding of the ICE Coastal Management Conference, Amsterdam.

Whitehouse R, Balson P, Beech N et al. (2009). "Characterisation and prediction of large scale long-term change of coastal geomorphological behaviours: final science report". Report SC060074/SR1, Environment Agency, ISBN 978-1-84911-090-7. 